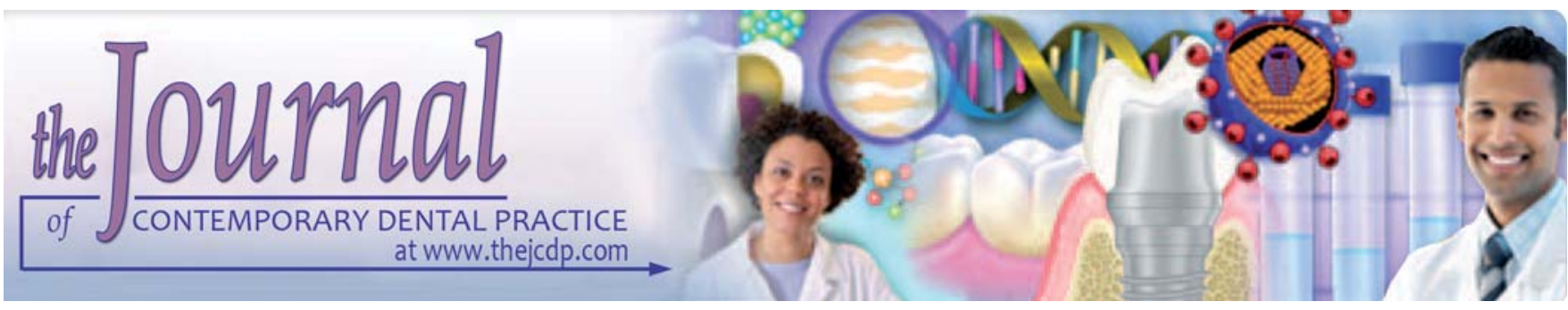

\title{
Effect of Different Impression Techniques on the Dimensional Accuracy of Impressions using Various Elastomeric Impression Materials: An in vitro Study
}

Kishan Singh, Sukant Sahoo, KD Prasad, Meenu Goel, Anupam Singh

\begin{abstract}
Production of exemplary crowns and fixed partial dentures depends upon the usage of impression material and its technique of usage that accurately reproduces prepared teeth and their relationship to the adjacent oral structure.
\end{abstract}

Aim: To evaluate the linear dimensional accuracy of the elastomeric impressions using various impression techniques using different combinations of viscosities of impression materials.

Materials and methods: Crown preparation was done in a dentulous acrylic resin denture base model with six natural teeth embedded into it was made to represent the dentulous maxillary arch. A total of 55 impressions were obtained and poured in die stone using various impression techniques with different combinations of viscosities of impression materials.

Results: Among the six techniques used, the heavy body light body two-step technique using custom tray showed the least distortion which was closely followed by the putty wash two-step technique with $2 \mathrm{~mm}$ spacer using stock tray.

Conclusion: The study revealed that the heavy body light body two-step technique with custom tray provided the best results.

Clinical significance: Dimensional accuracy of impressions is very much required for precisely fitting of prosthesis. This study may be helpfull to select the technique and materials as per clinical requirement of accuracy of impressions.

Keywords: Impression techniques, Polyvinyl siloxanes.

How to cite this article: Singh K, Sahoo S, Prasad KD, Goel M, Singh A. Effect of Different Impression Techniques on the Dimensional Accuracy of Impressions using Various Elastomeric Impression Materials: An in vitro Study. J Contemp Dent Pract 2012;13(1):98-106.

Source of support: Nil

Conflict of interest: None declared

\section{INTRODUCTION}

One of the most critical aspects of dentistry is the restoration that does not fit the preparation. Production of exemplary crowns and fixed partial dentures depends upon the usage of impression material and its technique of usage that accurately reproduces prepared teeth and their relationship to the adjacent oral structure.

In recent years, addition silicone impression materials have been reported to be most accurate in dimensional stability and surface reproduction. A large percentage of its success is attributed to its excellent physical properties and handling characteristics. ${ }^{1}$ Addition silicone was introduced as a dental impression material in the 1970s. In contrast with condensation silicones, addition reaction polymer is terminated with vinyl groups and is cross-linked with hydride groups activated by a platinum salt catalyst, so they are also called as polyvinyl siloxanes. Polyvinyl siloxanes became extremely popular during the past decade. These materials have excellent physical properties. Their accuracy is unsurpassed and they can record finer details. They also have the best elastic recovery, of all available impression materials. Because there is virtually no byproduct to the polymerization reaction, these impressions are dimensionally stable. ${ }^{2-5}$

The accuracy of this impression material largely depends upon the technique and the type of tray used. Various techniques have been used for making impressions. They have been broadly classified into three groups that are putty wash systems, single mix and the double mix technique with each technique showing clinically acceptable results. In this study, five different impression techniques were selected. Different clinical situations demand the utilization of different impression techniques, with each technique having its own advantages and disadvantages.

Hence, this study has been undertaken to try to understand and analyze the dimensional accuracy of the 
impressions using various impression techniques and impression materials with corresponding trays.

\section{MATERIALS AND METHODS}

Materials have been taken in this study to comparatively standardize the result, are reprosil and accurate as per Table 1 . The putty consistency is available in jars with volume measured by the scoops. All other consistencies are dispensed in tubes. All these materials are commercially available and recommended for use in making dental impressions.

The techniques for making impressions used were:

- Putty/wash two-step technique with polyethylene spacer

- Putty/wash-one-step technique

- Putty/wash-two-step technique with 2 mm spacer

- Medium body impression technique-1 step

- Medium body and light body combination-one-step

- Heavy body and light body combination-two-step technique.

For brand 1, all the six techniques have been used and for brand 2, five of the above-mentioned techniques have been used. The heavy body light body two-step technique cannot be used for brand 2 because the heavy body is not manufactured by the company.

\begin{tabular}{lll} 
& \multicolumn{2}{c}{ Table 1: Material } \\
\hline Trade name & Viscosities & Manufacturer \\
\hline Reprosil & Putty & Dentsply Caulk, USA \\
Reprosil & Heavy body & Dentsply Caulk \\
Reprosil & Medium body & Dentsply Caulk \\
Reprosil & Light body & Dentsply Caulk \\
Accurate & Putty & Made in Germany \\
Accurate & Monophase & Made in Germany \\
Accurate & Light body & Made in Germany \\
\hline
\end{tabular}

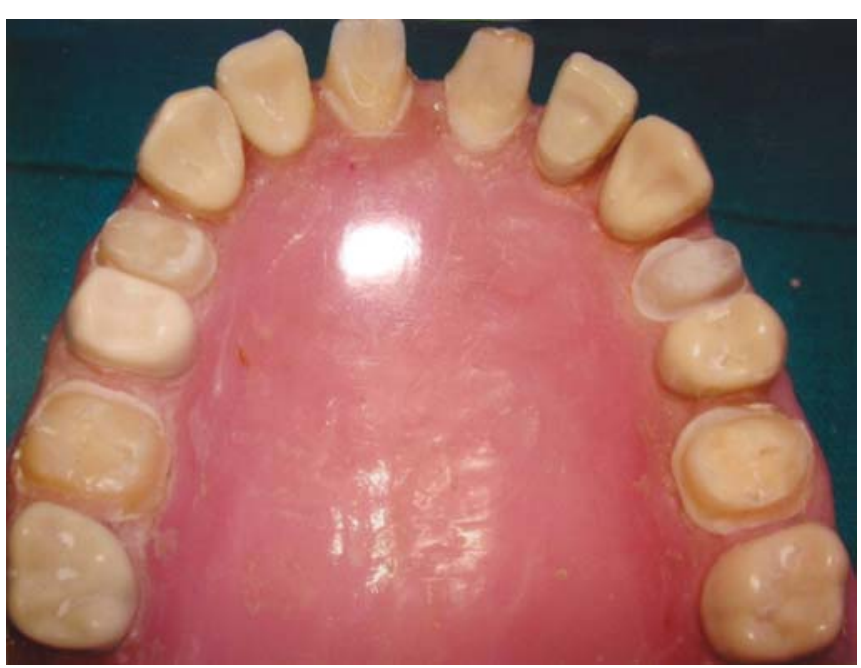

Fig. 1: Crown preparations done on the master model with reference points

\section{PREPARATION OF DIE MODEL}

1. A dentulous acrylic resin denture base model with six natural teeth represents the dentulous maxillary arch. Crown preparation was done for six natural teeth and occlusal plane was made flat for the enhancement of preparation of cross grooves as reference points (Fig. 1).

2. Two reference points for cast measurement were provided on the incisal edges of the two central incisors and two at the junction of cross grooves prepared on the premolar and molar to measure the interabutment distance. Reference points were also prepared on the finish line of the central incisor to measure the intraabutment distance (Fig. 2).

3. The anteroposterior dimension was measured from the point made on the incisal edge of the central incisor to 1st molar on both the sides, i.e. AE and BD.

4. Lateral dimensions were measured from the reference point made on the first premolar and molar of one side to that of the first premolar and molar on the contralateral side, i.e. DE and CF.

5. Vertical dimensions were measured from the point on the incisal edge of the central incisor to the point on the finish line of it, i.e. AA1 and BB1.

\section{IMPRESSION MAKING}

A total of 55 impressions were obtained five impressions for each technique.

For group 1, two-step technique was used with a polyethylene spacer. A polyethylene spacer $(0.3 \mathrm{~mm})$ supplied by the manufacturer was placed over the master model. The putty was kneaded and placed on the stock tray. The stock tray with putty was placed on the master model and allowed to set for 10 minutes. After this the spacer was removed, light body was then mixed utilizing mixing pad

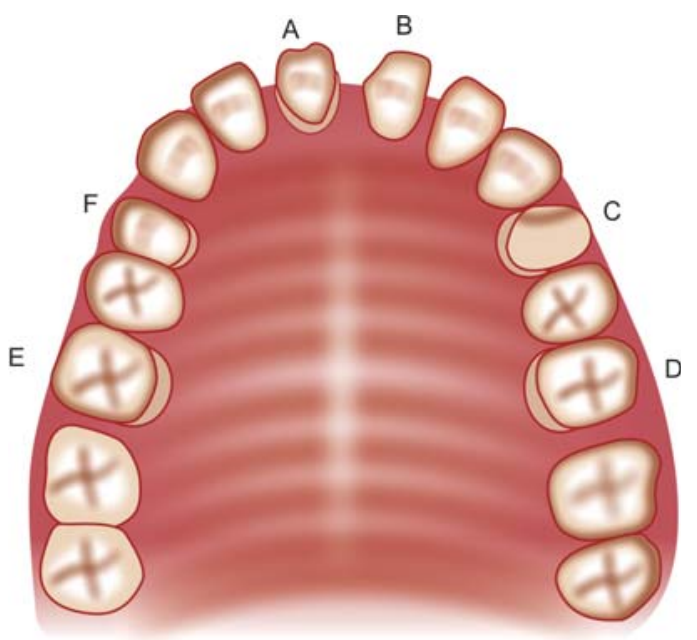

Fig. 2: Diagrammatic representation of the master model 
and spatula and syringed on to the tooth surface and the set putty. The set putty was then placed over the master model and allowed to set for 12 minutes.

For group 2, impressions were subjected to one-step technique. Putty was kneaded and loaded onto the stock tray; at the same time an assistant mixed the wash material and dispensed with the syringe on the tooth surface and the palatal surface of the master model. Now the stock tray loaded with putty was seated over the master model and was allowed to set for 12 minutes.

For group 3, the two-step technique with $2 \mathrm{~mm}$ relief was used. A $2 \mathrm{~mm}$ thick vacuum formed plastic (Bioplast) was adapted to the stone cast by using sta-vacuum former machine to provide a uniform $2 \mathrm{~mm}$ space for the wash impression material. The putty impression was initially made on the master model with the spacer placed on the tooth and it was allowed to set for 10 minutes. Then the spacer was removed and the light body impression material was mixed and dispensed with syringe on the tooth surface, with little applied on the set putty. After this set putty was reseated on the master model and the impression was allowed to set for 12 minutes.

For group 4, medium body one-step technique, on the prepared custom tray wax spacer was removed. Tray adhesive was applied and the tray was allowed to dry for 10 minutes. Then medium viscosity material was utilized both as tray and syringe material. The impression material was mixed utilizing mixing pad and spatula, some part of the material was loaded onto the syringe and applied over the tooth surface the remaining portion was placed into the custom tray. The tray was seated on the master model and allowed to set for 12 minutes.

For group 5, medium body light body one-step technique, on the prepared custom tray. The medium viscosity material was utilized as tray material and the light body viscosity was utilized as the syringe material. Medium body material was mixed and loaded on the custom tray and at the same time the assistant mixed the light body and syringed it on to the tooth surface and palatal surface of the master model. Then the tray was seated on the master model and allowed to set for 12 minutes.

For group 6, heavy body light body two-step technique, on the prepared custom tray. The heavy body and the light body material were utilized, heavy body as tray material and the light body as syringe material. First the heavy body material was mixed and loaded on to the custom tray which was then placed on the master model and allowed to set for 10 minutes. After the impression had set, sluiceways were cut, and then the light body was mixed and with the help of syringe was dispensed on to the teeth. Then the tray material was seated on the master model and allowed to set for 12 minutes (Fig. 3).
The same techniques were followed for the brand 2 impression materials except for the heavy body light body combination (Figs 4 and 5). All materials were mixed in standardized proportions according to the manufacturer's

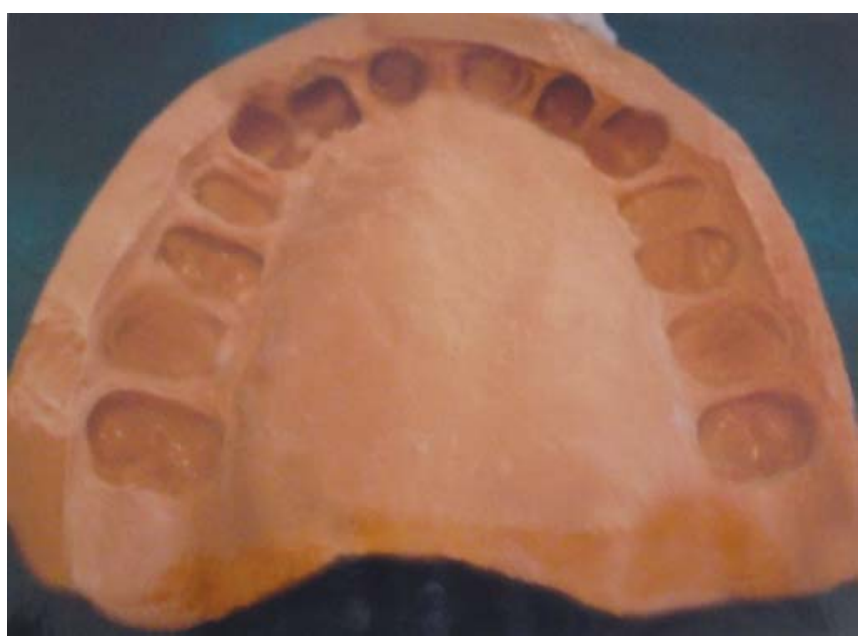

Fig. 3: Heavy body and light body-two-step technique with brand 1

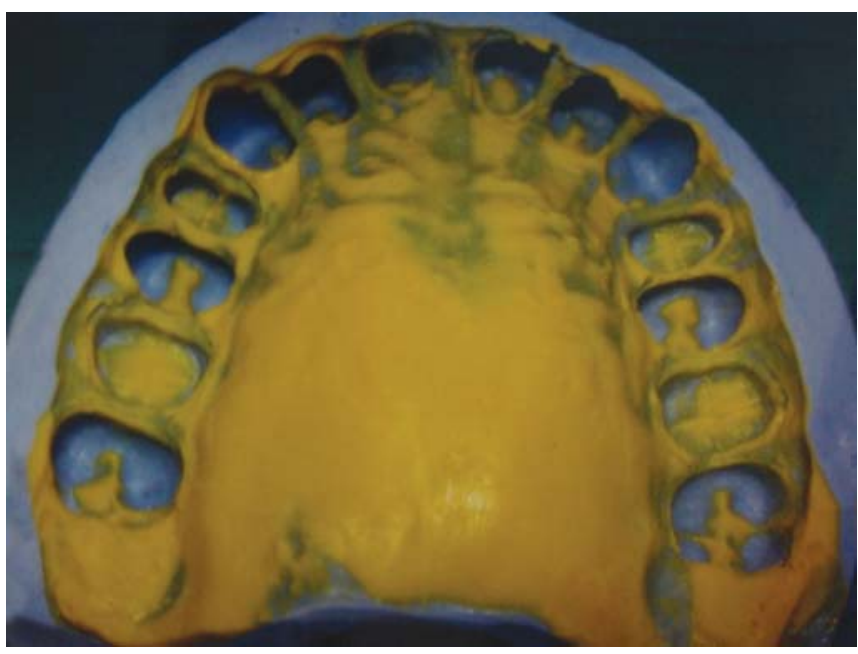

Fig. 4: Putty wash—one-step impression with brand 2

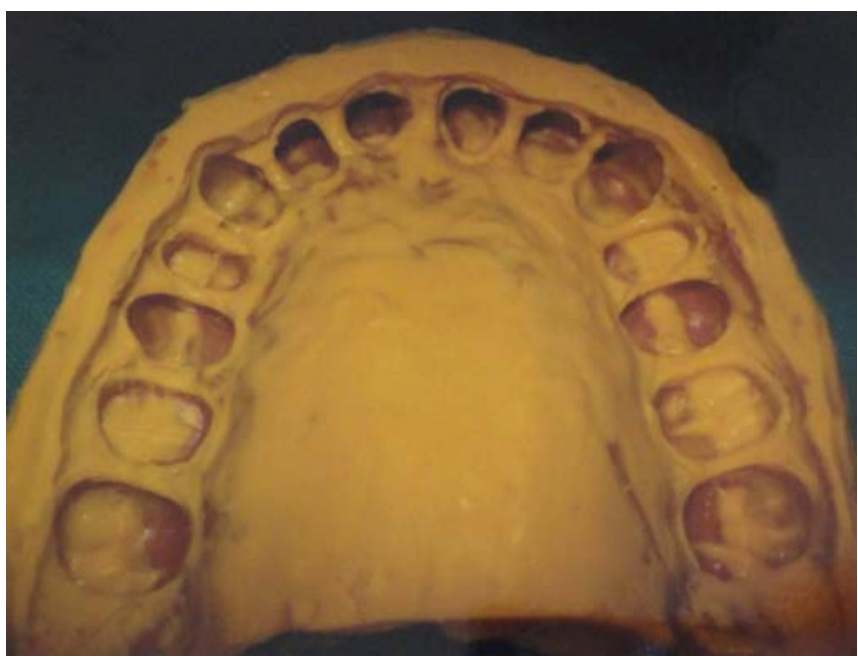

Fig. 5: Medium body and light body-one-step impression with brand 2 
recommendations. The tray adhesive supplied by the manufacturer was applied evenly over the tray surface. Setting time was increased according to manufacturer recommendations by keeping the material in the refrigerator. All impressions were stored at room temperature $\left(25^{\circ} \mathrm{C}\right)$ for 24 hours before being poured.

\section{GYPSUM CAST}

After 24 hours, these impressions were poured with high strength stone (Type IV, Kalrock). The die stone was mixed with a powder water ratio of $100 \mathrm{gm} / 22 \mathrm{cc}$ in a mixing bowl.

The accuracy of linear dimensional changes of different impression techniques of polyvinyl siloxanes was assessed on the cast made from impressions of acrylic resin master model. Reference points reproduced on the cast were subjected to measurements for the assessment of accuracy. The anteroposterior and lateral dimensions were measured with coordinate measuring machine to a precision of two decimals of a millimeter (Fig. 6). The vertical dimension was measured on a profile projector with a magnification which was ten times the normal size and the readings were recorded. Each measurement was repeated three times on the stone casts and master model. To eliminate individual variability all measurements were made by the same individual. The distance between these points on the master model was measured thrice and the mean value was recorded, as the standard value for each dimension, which acts as control group.

\section{DATA ANALYSIS}

The entire results section is divided in to four parts namely:

- Part I: Comparison between techniques

- Part II: Comparison between brands

For part I, since there were more than two groups to be compared, One-way ANOVA test was employed. For

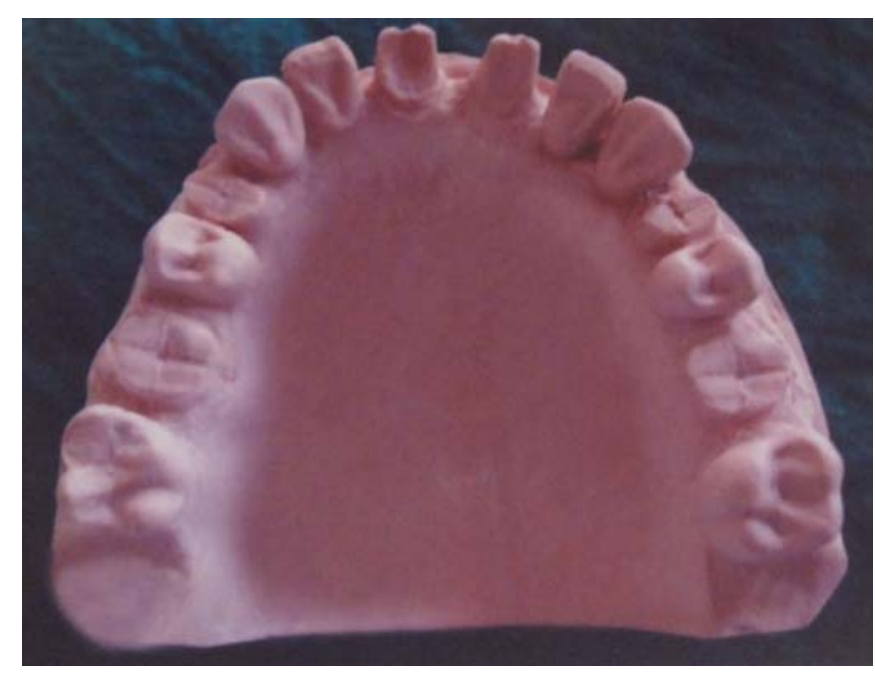

Fig. 6: Cast obtained part II, since there were only two group means to be compared, independent samples t-test was employed to find out the difference between two group means. All the statistical analysis was done with the help of software SPSS version 10.0.1 for Windows (Statistical Presentation System Software, New York, 1999).

\section{RESULTS}

The three dimensions of each impression technique were compared with the master model utilizing descriptive statistics and the mean and standard deviations were recorded. Table 2 shows mean and SD values for parameter $\mathrm{AE}, \mathrm{BD}, \mathrm{DE}, \mathrm{CF}, \mathrm{AA} 1$ and BB1 along with results of ' $\mathrm{F}$ ' test.

\section{Part I: Comparison between Techniques}

Table 3 shows mean and amount of distortion values for parameter $\mathrm{AE}, \mathrm{BD}, \mathrm{DE}, \mathrm{CF}, \mathrm{AA} 1$ and $\mathrm{BB} 1$ values for different techniques along with results of ' $\mathrm{F}$ ' test.

- $A E$ and BD: One-way ANOVA revealed a highly significant difference in AE $(F=296.002$; $p<0.000)$ for mean values of different techniques. The mean $\mathrm{AE}$ values clearly revealed that technique VI values were found to be very near to the master model, followed by technique III. The mean values of technique II were found to be farthest from the master model toward lower direction, whereas mean value of technique $\mathrm{V}$ was found to be farthest from master model on the upper side. This trend is clearly shown in Graph 1.

In the case of $\mathrm{BD}$, One-way ANOVA revealed a highly significant difference $(\mathrm{F}=267.915$; $\mathrm{p}<0.000$ ) for mean $\mathrm{BD}$ values of different techniques. The mean $B D$ values clearly revealed that technique VI values were found to be very near to the master model, followed by technique III. The mean values of technique II were found to be farthest from the master model toward lower direction, whereas mean value of technique $\mathrm{V}$ was found to be farthest from master model on the upper side. This trend is clearly shown in Graph 1.

- DE and CF: One-way ANOVA revealed a significant difference in $\mathrm{DE}(\mathrm{F}=16.795$; $\mathrm{p}<0.000)$ for mean values of different techniques. The mean DE values clearly revealed that technique III values were found to be very near to the master model. The mean values of technique II were found to be farthest from the master model toward lower direction, whereas mean value of technique VI was found to be farthest from master model on the upper side. This trend is clearly shown in Graph 2.

In the case of CF, One-way ANOVA revealed a significant difference $(F=17.208 ; \mathrm{p}<0.000)$ for mean 


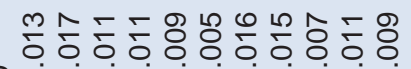

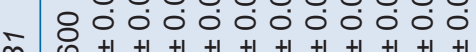

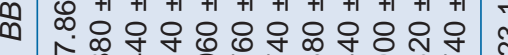

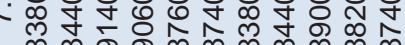

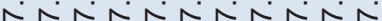

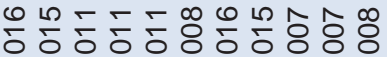
480000000000000

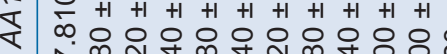
r.

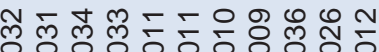
o. 0.000000000 U.

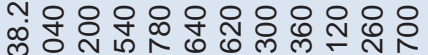
m 곡

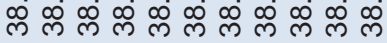

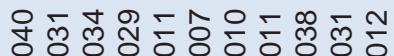

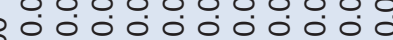

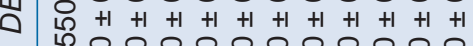

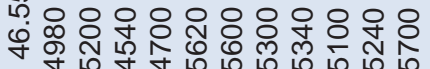

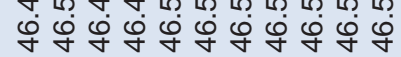

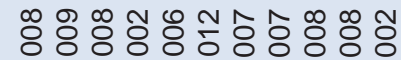

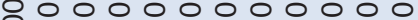

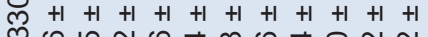

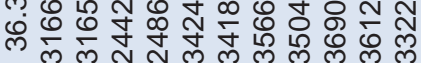

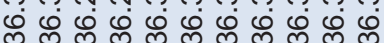

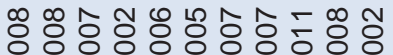
س

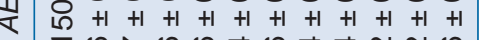

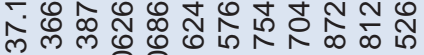

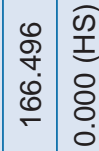

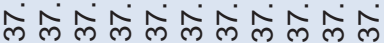

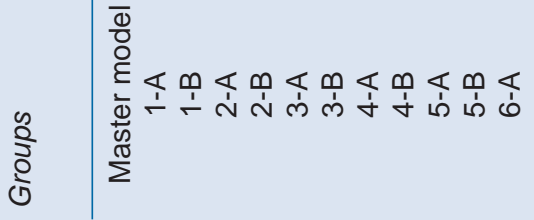

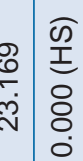

离

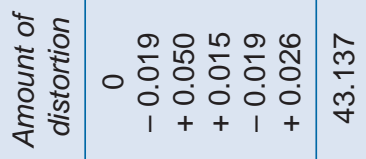

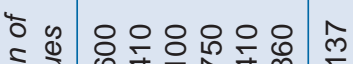

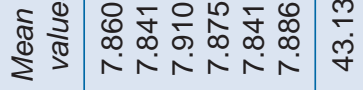

간

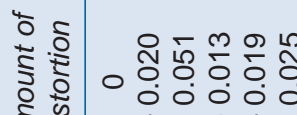
更

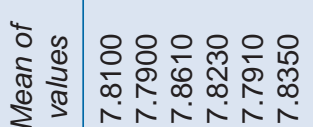

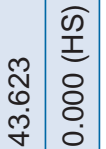
ù

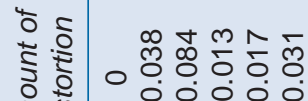
है

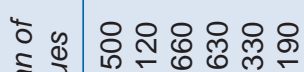
$\infty$

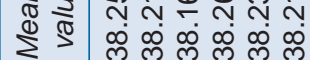

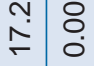
岁

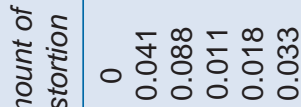
है

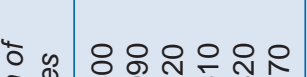

()

ส 守 守 守守守 $\begin{array}{ll}0 & 8 \\ \dot{6} & 8 \\ 0\end{array}$

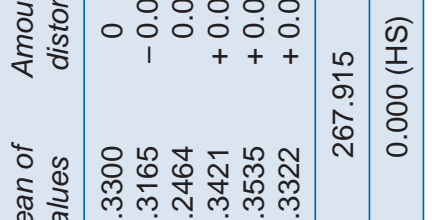
之一

ปิ

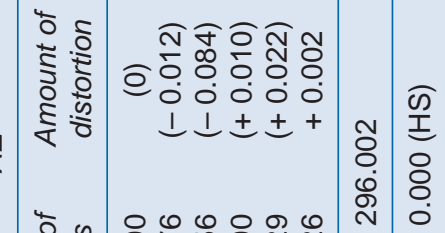

¿

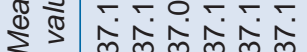

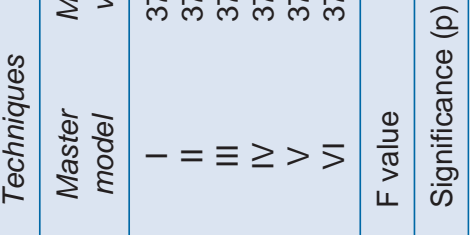


$\mathrm{BD}$ values of different techniques. The mean CF values clearly revealed that technique III values were found to be very near to the master model. The mean values of technique II were found to be farthest from the master model toward lower direction, whereas mean value of technique VI was found to be farthest from master model on the upper side. This trend is clearly shown in Graph 2.

- $A A 1$ and BB1: One-way ANOVA revealed a highly significant difference in AA1 ( $F=43.623 ; \mathrm{p}<0.000)$ for mean values of different techniques. The mean AA1 values clearly revealed that technique VI values were found to be very near to the master model, followed by technique III. The mean values of technique I were found to be farthest from the master model towards lower direction, whereas mean value of technique II was found to be farthest from master model on the upper side. This trend is clearly shown in Graph 3.

In the case of BB1 also, One-way ANOVA revealed a highly significant difference $(\mathrm{F}=43.137 ; \mathrm{p}<0.000)$ for mean BB1 values of different techniques. The mean

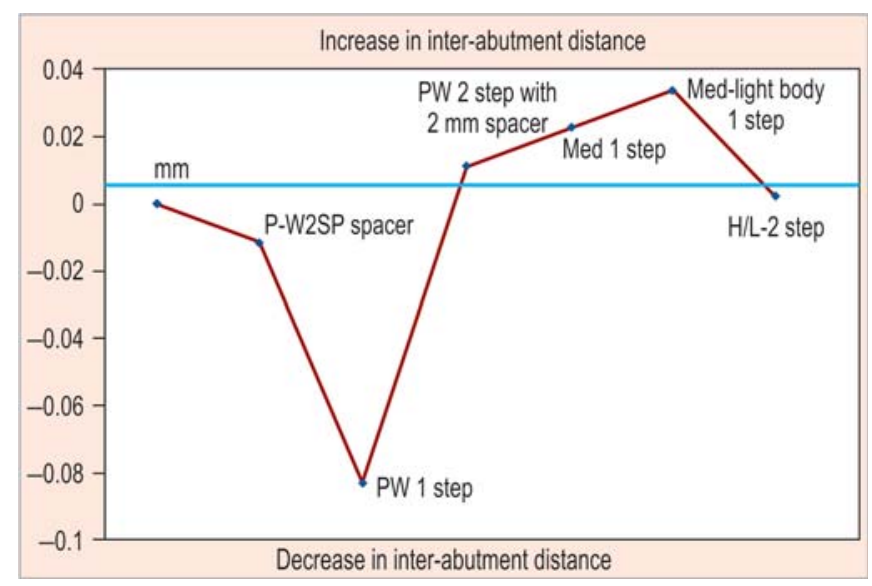

Graph 1: Mean values of anteroposterior dimension (inter-abutment distance) with various techniques

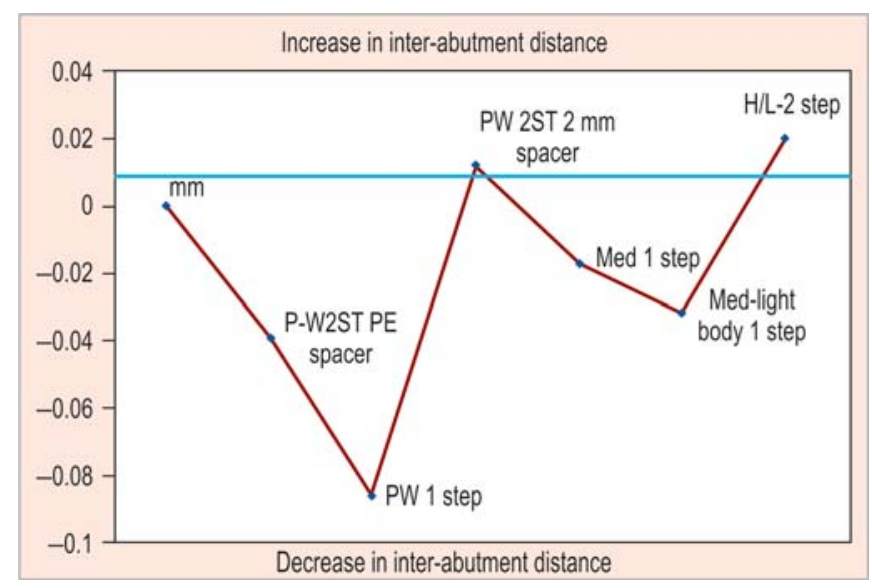

Graph 2: Mean values of lateral dimension (inter-abutment distance) with various techniques

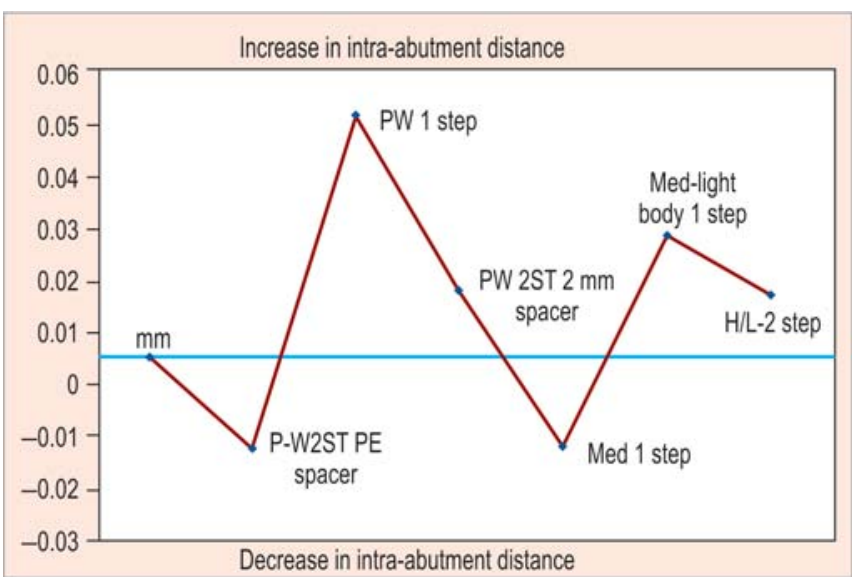

\begin{tabular}{|c|c|}
\hline MM & Master model \\
\hline PW2ST PE spacer & $\begin{array}{l}\text { The putty wash two step with } 0.3 \mathrm{~mm} \\
\text { polyethylene spacer }\end{array}$ \\
\hline PW one step & Putty wash one-step technique \\
\hline PW2ST 2 mm spacer & Putty wash two step with $2 \mathrm{~mm}$ spacer \\
\hline Med one step & Medium body one step \\
\hline Med-light body one step & Medium body and light body one step \\
\hline H/L-two step & Heavy body and light body two step \\
\hline
\end{tabular}

Graph 3: Mean values of vertical dimension (intra-abutment distance) with various techniques

BB1 values clearly revealed that technique VI values were found to be very near to the master model, followed by technique III. The mean values of technique IV were found to be farthest from the master model towards lower direction, whereas mean value of technique II was found to be farthest from master model on the upper side. This trend is clearly shown in Graph 3.

\section{Part II: Comparison between Brands}

The independent samples t-test was performed for two brands for all the six parameters. Table 4 presents mean of $\mathrm{AE}, \mathrm{BD}, \mathrm{DE}, \mathrm{CF}, \mathrm{AA} 1$ and $\mathrm{BB} 1$ values under different brands along with results of independent samples t-test.

- $A E$ and $B D$ : The independent samples t-test revealed a nonsignificant difference for mean AE values of brand 1 and 2 materials $(t=0.252 ; \mathrm{p}<0.802)$. As in the case of $\mathrm{AE}$, in $\mathrm{BD}$ values also, the independent samples t-test revealed a nonsignificant difference for mean BD values of brand 1 and 2 ( $\mathrm{t}=0.277 ; \mathrm{p}<0.783)$.

- $D E$ and CF: The independent samples t-test revealed a nonsignificant difference for mean $\mathrm{DE}$ values of brand 1 and 2 ( $t=0.080 ; p<0.936)$. In the case of CF also, the independent samples t-test revealed a nonsignificant difference for mean CF values of brand 1 and $2(t=0.184$; $\mathrm{p}<0.855)$.

- $A A 1$ and BB1: The independent samples t-test revealed a nonsignificant difference for mean AA1 values of brand 1 and $2(t=0.360 ; p<0.720)$. In the case of BB1, 
also the independent samples t-test revealed a nonsignificant difference for mean BB1 values of brand 1 and $2(\mathrm{t}=0.261 ; \mathrm{p}<0.795)$.

\section{DISCUSSION}

Making an impression represents a crucial step in processing and fitting dental prosthesis. For that reason, the quality of the impression is decisive for final fitting accuracy, and consequently for the success of the dental reconstruction. Several techniques have been developed to improve the accuracy of impressions used in making crowns and fixed partial dentures. Interest has grown in a new group of impression materials called addition silicones since they have shown to be accurate and dimensionally stable. These addition silicone impression materials are currently available in several viscosities leading to at least three choices for impressions (A) putty-wash, (B) single-mix impression, (C) double-mix impression. These three general techniques combined with several combinations for trays and viscosities present a dilemma to the dentist. To date, research on addition silicone has concentrated on the properties of the materials and little information is available on the effect of viscosity and tray selection on the accuracy. In the present study, an effort has been made to find out the most accurate technique. Six impression techniques using polyvinyl siloxane impression materials in fixed prosthodontics were used in this study.

Out of the six techniques studied, there was an increase in the interabutment distance for anteroposterior dimension which was seen in four groups, i.e. group III putty wash two-step with $2 \mathrm{~mm}$ spacer, group IV, i.e. medium body single-step technique, group $\mathrm{V}$, i.e. medium body and light body one-step technique, group VI, i.e. heavy body and light body two-step technique with group VI showing the least distortion followed by group III. Johnson and Craig ${ }^{6}$ found out in their study that the heavy body light body two-step technique showed slightly more accurate results as compared to the other techniques. They said that this result was because of the control of the bulk of the impression material. There was a decrease in the inter abutment distance seen in two groups, i.e. group I, i.e. putty wash two-step with polyethylene spacer and group II, i.e. putty wash onestep technique with group II showing the maximum distortion (Graph 1). This is in accordance with the present study. Shirley H Hung and John H Purk ${ }^{7}$ in their study concluded that the putty wash impression one-step technique shows a lot of distortion.

For the lateral dimension (Graph 2), there was an increase in the inter-abutment distance seen in two groups, i.e. group III, i.e. putty wash two-step with $2 \mathrm{~mm}$ spacer and group VI, i.e. heavy body and light body two-step technique with group III showing the least distortion. Joseph Nissan, Benzian Laufuer and Tamar Brosh ${ }^{8}$ in their study found out that the overall discrepancy of the two-step technique with $2 \mathrm{~mm}$ relief putty wash impression technique was significantly smaller than that in one step and polyethylene putty wash impression technique. They studied that group III showed the most accurate values for the lateral dimension and this good result was attributed to the controlled amount ( $2 \mathrm{~mm}$ ) of wash material. The wash stage which is carried out after the putty has set and contracted served as a custom tray. The controlled bulk compensates for this contraction with minimum dimensional changes. This is similar to the present study. Tjan AHL and Whang, ${ }^{9}$ Johnson and Craig ${ }^{6}$ in a study concluded that the same accuracy was achieved for all the techniques, i.e. the putty wash single mix and double mix. There was a decrease in the inter-abutment distance seen in four groups, i.e. group I-putty wash two-step with polyethylene spacer, group IV, i.e. medium body single step technique, group V, i.e. medium body and light body one-step technique and group II, i.e. putty wash one step technique with group II showing the maximum distortion. Barry Marshall and David Assif ${ }^{10}$ in their study said that group I which was putty wash two-step technique with polyethylene spacer showed that the wash bulk was not controlled which may allow for differential contraction that results in uneven dimensional changes. Group IV which was single mix medium viscosity impression technique in a custom tray produced reasonably accurate results apart from the anteroposterior dimension. Andy Piwovarcyk, Peter $\mathrm{OH}$ and Alfred Buchler ${ }^{11}$ in their

\begin{tabular}{cccccccrrr}
\multicolumn{7}{c}{ Table 4: Mean values and results of independent samples t-test of anteroposterior lateral and } \\
vertical dimension for various materials (in mm)
\end{tabular}


study gave a possible explanation for the reasonable accuracy that is due to a bulk amount of the single-viscosity material may have more polymerization shrinkage than a bulk amount of the putty or the heavy body material that have higher filler contents. The above study correlates with the present study.

For the vertical dimension (Graph 3), there was an increase in the intra-abutment distance in four groups, i.e. group II-putty wash one step technique, group III, i.e. putty wash two-step with $2 \mathrm{~mm}$ spacer, group $\mathrm{V}$, i.e. medium body and light body one-step technique, group VI, i.e. heavy body and light body two-step technique with the results of group VI being closest to the master model followed closely by group III. There was a decrease in the intra-abutment distance of two groups, i.e. group I-medium body singlestep technique and group IV, i.e. medium body single-step technique. In a study by Idris Houston and Claffey, ${ }^{12}$ they compared the putty wash one step and two step techniques and showed that there was a decrease in the intra-abutment distance which is in accordance with the present study.

Mitchell and Damele ${ }^{13}$ in their study stated that the distortion was produced not because of the impression technique but because of shrinkage of impression material toward the attachment of tray. This is similar to the present study. De Araujo and Jorgensen ${ }^{14,15}$ stated that the amount of thickness of impression material is more relevant as compared to the technique used. They said that an increase in thickness from 1 to $4 \mathrm{~mm}$ causes a greater distortion. Joseph Nissan, Benzian Laufuer and Tamar Brosh; ${ }^{8}$ Idris Houston and Claffey ${ }^{12}$ from their study concluded that accuracy of impression was affected by technique and some authors like Johnson, Craig, ${ }^{6}$ Tjan et al, ${ }^{9}$ Hung et al, ${ }^{16}$ Mitchell and Damale ${ }^{13}$ said that technique did not play a significant role in relation to the accuracy of impression material.

From the above study, it could be made out that group III and group VI showed more accurate results as compared to others. But all of them were acceptable under the clinical limits of accuracy.

In this study, not much emphasis is made on the comparison of brands. Through the results obtained, we can see that there was hardly any statistical significant difference between the two brands used, i.e. brand 1 and 2 (Table 4). This may be attributed to a reason that there is not much of a difference in the filler content of the various viscosities of impression materials used by the different companies.

\section{CONCLUSION}

Under the conditions of these investigations and based on the study results, the following conclusions can be made.

This study revealed that the heavy body light body twostep technique with custom tray provided the best results with the mean of amount of distortion as compared to the master model being $0.011 \mathrm{~mm}$, this was closely followed by putty wash two-step technique with $2 \mathrm{~mm}$ spacer using stock tray with the mean of amount of distortion being $0.012 \mathrm{~mm}$.

This study showed that the putty wash one-step technique with the stock tray showed the maximum amount of distortion to value more than $50 \mu \mathrm{m}$.

However, further studies with different products and parameters need to be done before generalization regarding the accuracy of impression techniques and the necessity of custom tray in fixed, removable and maxillofacial prosthodontics.

\section{CLINICAL SIGNIFICANCE}

Dimensional accuracy of impressions is very much required for precisely fitting of prosthesis. The impression technique plays a great role to achieve the accuracy of impression along with the impression materials used. Hence, this study may be help full to select the technique as per clinical requirement of accuracy of impression.

\section{REFERENCES}

1. MC Cabe IF, Wilson HJ. Addition silicone impression material an appraisal of physical properties. Br Dent J 1978;145:17-20.

2. Anusavice KJ. Philips science of dental materials (10th edn). WB Saunders Co Philadelphia 1996.

3. Chee WWL, Donovan TE. Polyvinyl siloxane impression materials. A review of properties and techniques. J Prosthodont 1992;68:728-32.

4. Council on dental materials, instruments and equipment. Polyvinyl siloxane impression materials: A status report. J Am Dent Assoc 1978;12:595-96, 598-600.

5. Wassel RW, Ibbleston RJ. The accuracy of polyvinyl siloxane impression made will standard and reinforced tray. J Prosthet Dent 1991;65:748-57.

6. Boulton JL, Gage JP, Vicent PF, Basford KE. A laboratory study of dimensional changes for the elastomeric impression materials using custom and stock trays. Aust Dent J 1996;41:398-404.

7. Hung SH, Purk JH, Tira DE, Eick JP. Accuracy of one step versus 2 step putty wash addition silicone impression technique. J Prosthet Dent 1992;67:583-89.

8. Joseph Nissan, Benzian Laufer, Tamar Brosh, David Assif. Accuracy of three polyvinyl siloxane putty wash impression techniques. J Prosthet Dent 2000;83:161-65.

9. Tian AHL, Whang B. Clinically oriented evaluation of accuracy of commonly used impression material. J Prosthet Dent 1986;53: 784-90.

10. Barry Marshak, David Assif, Raphael Pilo. A control putty wash impression technique. J Prosthet Dent 1990;64:635-36.

11. Andry Piwowarayk, Peter OH, Alfred Buchler, Hans Christopher. In vitro study on the dimensional accuracy of selected materials for monophase elastic impression making. Int J Prosthodont 2002;15:168-74.

12. Idris Houston, Claffey. Comparison of dimensional accuracy of one step versus two-step technique with the use of putty wash addition silicone impression material. J Prosthet Dent 1995;74: $535-41$. 
13. Mitchell JV, Damele JI. Influence of tray design on elastic impression material. J Prosthet Dent 1970;23:51-57.

14. De Araujo PA, Jorgensen KD. Effect of materials bulk and undercuts on the accuracy of impression materials. J Prosthet Dent 1985;54:791-94.

15. De Araujo PA, Jorgensen KD. Improved accuracy by reheating addition-reaction silicone impressions. J Prosthet Dent 1986;55:11-12.

16. Eames WB, Sieweke JC, Wallance SW, Rogersl B. Elastomeric impression materials: Effect of bulk on accuracy. J Prosthet Dent 1979;42:304-07.

\section{ABOUT THE AUTHORS}

\section{Kishan Singh (Corresponding Author)}

Professor and Head, Department of Prosthodontics, Shree Bankey Bihari Dental College, Ghaziabad, Uttar Pradesh, India, Phone: 09837572141, e-mail: drkpsingh.principal@gmail.com

\section{Sukant Sahoo}

Associate Professor, Department of Prosthodontics, Shree Bankey Bihari Dental College, Ghaziabad, Uttar Pradesh, India

\section{KD Prasad}

Professor and Head, Department of Oral Pathology, Shree Bankey Bihari Dental College, Ghaziabad, Uttar Pradesh, India

\section{Meenu Goel}

Senior Lecturer, Department of Prosthodontics, Saraswati Dental College and Hospital, Lucknow, Uttar Pradesh, India

\section{Anupam Singh}

Senior Lecturer, Department of Prosthodontics, Shree Bankey Bihari Dental College, Ghaziabad, Uttar Pradesh, India 